\title{
TEORÍA DEL DERECHO Y SOCIOLOGÍA DEL DERECHO: EL DICTIONNAIRE D'EGUILLES
}

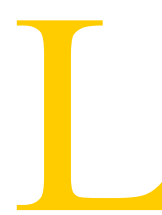

as relaciones entre teoría y sociología del Derecho, aun sin desconocer la importancia de no pocas aproximaciones a la cuestión ${ }^{1}$ constituyen todavía hoy un campo de trabajo que viene exigiendo un análisis detallado. Quizá por ello sea particularmente interesante el esfuerzo que un grupo de profesores e investigadores de diferentes países, bajo la dirección de André-Jean Arnaud, ha llevado a cabo para elaborar la obra que comentamos, el Diccionario de Eguilles, un diccionario de teoría y sociología del Derecho ${ }^{2}$. Por lo demás, se trata de un problema que hoy, entre nosotros, tiene una cierta actualidad por cuanto se han vuelto a plantear -esta vez a escala puramente académica, con motivo de la reforma de los planes de estudio de las Facultades de Derecho- las relaciones entre Filosofía del Derecho, Teoría del Derecho y, aunque esto desde luego con carácter residual, Sociología del Derecho.

Desde luego, no es una novedad el intento de ofrecer una Enciclopedia, Diccionario o Lexicón jurídico ${ }^{3}$. Sí lo es, en cambio, el tratar de proporcionar una obra de esa naturaleza pero especializada (al modo, por ejemplo, en que existe el Diccionario

${ }^{1}$ P. ej., Kelsen/Duguit, 1926 (es el prólogo de la revista destinada a fomentar ese intercambio, Droit et Société, hoy relanzada gracias, entre otros, al esfuerzo de A.-J. Arnaud). Sobre el problema de esas relaciones en la obra de Kelsen, además de Kelsen, 1912, 1928, 1986, cfr. Treves, 1985. También, sobre el replanteamiento de esas relaciones, Llewellyn, 1940; Hart, 1968; Bobbio, 1980, y, recientemente, Treves, 1988, y Ferrari, 1987, o Atienza, 1988.

${ }^{2}$ André-Jean (ed.), Dictionnaire encyclopédique de théorie et de sociologie du droit («dictionnaire d'Eguilles»), Librairie Générale de Droit et de Jurisprudence- E. Story-Scientia, Editions Juridiques et Fiscales, Paris-Bruxelles, 1988.

${ }^{3}$ Entre los existentes, cabe destacar las italianas Enciclopedia del Diritto, Novissimo Digesto, la española Enciclopedia jurídica Seix, el americano A Law Dictionary, de Bouvier, la más clásica Encyclopädie des Rechtswissenschaft, de Holtzendorff, o el Lexique des sciences sociales, de Grawitz, o el reciente Vocabulaire Juridique, dirigido por Cornu. 
de política, de Bobbio-Mateucci) y más concretamente, en los dos ámbitos mencionados. Por supuesto, al enfrentarse con un trabajo de este carácter es necesario, en primer lugar, tratar de encontrar la justificación de la delimitación temática: ¿por qué teoría y sociología del Derecho? Los autores del diccionario se han preocupado naturalmente de responder a ello, no sólo en el interesante prefacio de la obra, sino también en el prólogo de la nueva serie de la Revista fundada por Kelsen y Duguit en 1926, Droit et Société. La elección de teoría del Derecho como objeto específico se basaba, en la declaración de Kelsen y Duguit, en la necesidad de abordar el estudio de «los problemas comunes a los derechos de todos los pueblos, problemas que se fundan en la naturaleza del Derecho, las relaciones entre Derecho, Estado y sociedad, las nociones fundamentales y métodos del conocimiento jurídico... una teoría del Derecho en sí, del Derecho puro que hace abstracción del fondo material, accidental y variado que acusa el Derecho en tal o cual Estado...» En resumen, la teoría del Derecho es entendida por Kelsen y Duguit como «postulado primero de todo estudio que se pretenda científico respecto a un sistema jurídico concreto» ${ }^{4}$. Además, se trata de Teoría y no Filosofía, por cuanto se persigue siempre una Teoría del Derecho positivo, apoyada en la experiencia, y además porque se excluye la reflexión especulativa sobre la justicia que constituiría el quehacer de esta última. Sin embargo, no es este el punto de vista de los autores del diccionario, que rechazan explícitamente el anatema de la separación de lo meta o extrajurídico en nombre de la pureza metodológica, que rechazan por ello la reflexión propia del modelo de la Dogmática jurídica, partiendo de una comprensión del Derecho como fenómeno histórico, cultural y social, además de lógico, que es posible abordar, pues, desde diferentes tipos de racionalidad. De ese punto de partida derivan diferentes conclusiones que importa señalar:

-En primer lugar, el carácter privilegiado, aunque no exclusivo, de las relaciones Derecho-Sociedad como objeto: el Derecho aun sin desconocer su carácter básicamente normativo, es un fenómeno social, histórico, cambiante. Es imposible comprenderlo sin estudiar el complejo de factores de los que es resultado e instrumento. Esta es, por otra parte, la razón esencial de la vinculación entre teoría y sociología del Derecho, ya que «una es indisociable de la otra»y, sobre todo, «la sociología jurídica

\footnotetext{
${ }^{4}$ Vid. el Prefacio cit. reeditado en la presentación de la nueva serie. Kelsen/-Duguit, 1926-1985.
} 
es uno de los intentos contemporáneos más interesantes para superar las contradicciones e insuficiencias de la teoría del Derecho que hemos heredado» ${ }^{5}$.

-Además, el estatuto científico, que no meramente técnico, de la teoría y sociología del Derecho, como saberes no dogmáticos y, sin embargo, aptos para la comprensión del objeto normativo. Si es no sólo necesario sino posible y útil superar la perspectiva dogmática para la comprensión del Derecho, ello se debe a la adopción de una perspectiva científica y no técnica (esto es, a la persecución no de utilidad inmediata, la que proporcionan unas categorías que sean funcionales para la práctica jurídica, sino a la «puesta en evidencia de las condiciones de emergencia y de los efectos del Derecho por procedimientos que no se fundamentan sino en premisas hipotéticas y no en hipóstasis» ${ }^{6}$ ). Ello supone, pues, partir de la comprensión de lo que se llama Dogmática o Ciencia del Derecho como técnica jurídica, como ha puesto de relieve entre nosotros, Atienza ${ }^{7}$ y eso es precisamente lo que lleva a reclamar otros criterios, instrumentos y objetivos si se quiere proporcionar un conocimiento científico del Derecho, objetivo que, precisamente, justifica la necesidad de acudir a la teoría y la sociología del Derecho.

-Finalmente, la necesidad que la teoría y la sociología del Derecho tienen de contar con las llamadas «ciencias auxiliares» del Derecho. Junto a la opción por Teoría del Derecho en lugar de Filosofía del Derecho que se justificaría por la exigencia de arrancar de una «sólida formación jurídica» ${ }^{8}$, esto es, del conocimiento de lo que llamamos Derecho, el diccionario se presenta sobre todo como «un diccionario de lo que aún recientemente se llamaba ciencias auxiliares del Derecho», título que, según confiesan los autores ${ }^{9}$, no se ha utilizado únicamente por evitar la connotación ancilar que continúa manteniendo la expresión, ya que, muy al contrario, en esta obra se parte del carácter fundamental

${ }^{5}$ Prefacio, 12.

${ }^{6}$ Droit et Société, 1986/1. Pref., pág. 12.

${ }^{7}$ Atienza, 1987.

${ }^{8}$ Prefacio, pág. XV. Desde luego, no es en ese prefacio donde se encuentran las razones de tal opción (que son más bien débiles, salvo la que hemos recogido expresamente), sino en la ya referida declaración de intenciones de la nueva serie de la revista Droit et Société. El problema es que, lógicamente, no coinciden unos y otros autores, lo que da lugar a que en el Dictionnaire de Eguilles podamos encontrar voces que no necesariamente muestran coincidencia con esos puntos de partida, como aludiremos más adelante.

${ }^{9}$ Prefacio, XIII. 
de los conocimientos que sobre la realidad jurídica proporcionan dichas disciplinas.

Obviamente, el diccionario ha de hacer frente, aunque se trate posiblemente de una empresa casi desesperada, a algunos riesgos comunes a este tipo de obras: el «mito de la precisión» ${ }^{10}$, el afán de uniformización de los conceptos, la ambición de recrear el léxico científico o la falta de operatividad. En mi opinión, el diccionario de Eguilles afronta con notables resultados estos problemas. Efectivamente, el doble propósito lexicográfico y didáctico que se persigue ${ }^{11}$ descarta el primero y el tercero de los riesgos mencionados, $\mathrm{y}$ relativiza el segundo, mientras que el método seguido para la selección de las voces y su exposición reduce el cuarto. En efecto, el objetivo lexicográfico no supone la pretensión de establecer prescriptivamente todo el léxico científico de la teoría y la sociología del Derecho, sino tan sólo ofrecer definiciones que permitan comprender el lenguaje de esas disciplinas, pero todo ello suficientemente matizado por la preocupación pedagógica de precisar «el carácter real, conceptual y estipulativo de los términos definidos» a la vez que «el entorno disciplinar y cultural del concepto, sus lazos eventuales con otras disciplinas, las principales acepciones históricas y contemporáneas, las vías [de análisis] más frecuentadas y la que permanecen $\sin$ explorar $\rangle^{12}$. Además, la exigencia de abandono-exclusión de toda pretensión prescriptiva relativiza ${ }^{13}$ el peligro de perseguir la construcción de un sistema de conceptos artificioso inevitablemente en su uniformidad y, además, el método seguido en la elaboración de las 209 voces ${ }^{14}$, así como los criterios que se emplean para la exposición, reducen el riesgo de círculo vicioso, de sistema de espejos, $\mathrm{y}$, por consiguiente, permiten un notable grado de operatividad. En efecto, por lo que respecta a la estructura interna de las voces, se ha seguido, como advierte Ferrari ${ }^{15}$ un procedimiento que, por así decirlo, actúa «de lo relativamente simple o complejo»: se ofrecen en primer lugar las mots-clé en las que se formulan las definiciones o los complejos de definiciones que permiten trazar los lindes del campo semántico (en sentido

${ }^{10}$ La expresión, como se recuerda en el propio prefacio, se debe al título de la obra de Melinkoff, The Myth of precision, a propósito precisamente de lo que los diccionarios significan.

${ }^{11}$ Prefacio, pág. 12.

${ }^{12}$ Ibid.

${ }^{13}$ Cfr., p. ej., Prefacio XVI.

${ }^{14}$ Cfr. Ibid., XV y ss.

${ }^{15}$ Ferrari, 1988. 
positivo y negativo: como se explica en el instructivo Prefacio, se trataba de responder a los problemas que plantea una situación que, respecto al arsenal conceptual en cuestión, se caracteriza por la vulgarización de los conceptos fuera de los límites precisos de su uso inicial, la balcanización o superespecialización en los lenguajes propios de las diferentes ramas de los saberes jurídicos, y la babelización, la hipertrofia en la creación de neologismos que en muchos casos no responden a un avance conceptual) sin afanes de actio finium regundorum característicos de la mentalidad academicista, pero sin incurrir en el totum revolutum en el que en ocasiones deviene la ya más que tópica apelación a la interdisciplinariedad. A ellas acompaña un cuadro de referencias conceptuales, lingüísticas e históricas, la problemática básica del término, los datos etimológicos y bibliográficos, así como las traducciones en los cuatro idiomas de trabajo -alemán, inglés, castellano e italianoy los correlatos que, casi siempre son de imprescindible lectura: no basta con leer una voz, sino, como se indica por los autores, «constelaciones» o grupos de voces. En la mayoría de los casos sigue un comentario propio del autor de cada voz. Desde luego, si atendemos al sistema de voces clave (Ciencia del Derecho, de F. Ost; Sociología del Derecho, de R. Treves; Filosofía del Derecho, de N. Bobbio; Teoría del Derecho, de M. van Hoecke; Dogmática jurídica, de A. Aarnio; Sistema jurídico, de M. Hartney y A. J. Arnaud; Funciones del Derecho, de V. Ferrari; Derecho, de A. J. Arnaud) que compondrían la serie de conceptos relacionados con el problema que básicamente me interesaba destacar, esto es, el modelo de Teoría del Derecho, sobre todo en relación con la Filosofía y la Sociología del Derecho, esas notas permiten advertir algunas matizaciones con respecto a la concepción anteriormente expuesta. Efectivamente, mientras el punto de vista que propone, por ejemplo, Ost sugiere que la teoría del Derecho realizaría la aproximación fundamental entre el lenguaje de la dogmática y el de las ciencias sociales, mediación que constituiría pieza fundamental de una ciencia jurídica interdisciplinar, lo que encajaría con el proyecto básico del diccionario, el análisis de Van Hoecke supondría una visión más global y sustantiva de la teoría del Derecho, en cierta contradicción, por ejemplo, no sólo con lo dicho, sino también con las tesis que desarrolla Bobbio en la voz que mencionaba más arriba.

Por supuesto, no podernos hacer repaso aquí de las voces desarrolladas, en la mayor parte de los casos por especialistas de reconocido prestigio, como MacCormick, Aarnio, Luhmann, Rottleuthner, Blankenburg, Friedman, Bobbio, Treves, Ferrari, 
Rebuffa, Jori, Pattaro, Gianformaggio, Pocar, Kalinowski, Wroblewski, Gessner, Carbonnier, Ost, Vande Kerchove, Campbell, Carty, Villey, Chevallier, Dufour, Commaille, Miaille o el propio Arnaud. Hay que pensar que se trata de más de 130 colaboradores que pertenecen a 22 países diferentes, con un lógico predominio de los representantes del área francófona (Francia, Bélgica y Canadá) pero equilibrado en buena medida por una veintena de representantes del mundo anglosajón y una importante presencia, por ejemplo, de estudiosos italianos o alemanes. En este sentido, como también subraya Ferrari, la notable sistematicidad del Dictionnaire (aun a pesar de las inevitables diferencias de estilo y, desde luego, de calidad), el nivel de homogeneidad en léxico y presentación, son buena prueba del desarrollo y autonomía alcanzados por esas disciplinas y del hecho de que las relaciones entre Teoría y Sociología del Derecho son tan necesarias como insoslayables.

\section{BIBLIOGRAFÍA}

Atienza, «Teoría y técnica de la legislación», en Teoría, 1988.

—, «Sociología jurídica y ciencia de la legislación» (en prensa).

Bobbio, Contribución a la teoría del Derecho, F. Torres, Valencia, 1980.

Ferrari, Funzioni del Diritto, Laterza, Bari, 1987.

—, Recension en Sociologia del Diritto, núm. 1, 1988, págs. 161-163.

Hart, El concepto de Derecho, Abeledo-Perrot, Buenos Aires, 1968.

Kelsen-Duguit, Presentación de la revista Droit et Société, núm. 1, 1926.

Kelsen, Der soziologische und der Juristische Staatsbegriff, 1928.

—, «Zur Soziologie des Rechts. Kritische Bemerkungen», en ARSP, 1912. págs. 601 y sigs.

- Teoría pura del Derecho, UNAM, México, 1986.

Llewellyn, «The normative, the Legal and the Law-Jobs. The problem of Juristic Method», Yale Law Journal, 1940, núm. 49, págs. 1355 y sigs.

Treves, «Hans Kelsen et la Sociologie du Droit», Droit et Société, 1/1985, págs. 15-27.

—, Sociología del Derecho. Orígenes, investigaciones, problemas, Ariel, Barcelona, 1988.

\section{DOXA 5 (1988)}

